\title{
RAPPORT MANAGEMENT IN THAI AND JAPANESE SOCIAL TALK DURING GROUP DISCUSSIONS
}

\author{
Ataya Aoki
}

\begin{abstract}
According to Hofstede's (2003) often quoted survey, Japanese and Thai cultures rank high on the collectivist scale and both cultures attach the greatest importance to group harmony. Accordingly, we should see similar characteristics in Japanese and Thai speakers during discussions within their respective social groups. However, this is not the case. This paper examines social talk during the task-oriented interaction of Japanese and Thai speakers. The analysis focuses on how the speakers of Japanese and Thai present themselves and construct rapport in casual group talk. Using the concept of consciousness deployed in 'idea units' (Chafe 1980, 1994) and some semantic considerations, I identify three major differences in rapport construction between Japanese and Thai speakers. First, Japanese participants prefer to build common ground through discussion of communal topics and through dealing with the comprehensiveness and the orderliness of the situation, whereas Thai participants incline toward Individual-oriented topics and independent styles of talk. Second, the Japanese show a preference for using softening devices and conventionalized expressions in group discussion while the Thais tend to use intensifiers and spontaneous expressions to indicate involvement and create a friendly and fun atmosphere. Third, the Japanese like to demonstrate the minimization of self and the relevancy between the self and the collective whereas the Thais value the capitalization of the self and the strengthening of personal relationships. Japanese and Thai communicative styles can be viewed as reflection of the different way the two cultures conceptualize the notion of rapport and the self. With regard to the component of rapport management (Spencer-Oatey 2000), the Japanese place more emphasis on the observation of sociality rights, while the Thais incline toward the management of face. This suggests that rapport construction in collectivist cultures may possess totally different characters.
\end{abstract}

Keywords: Japanese; Thai; Rapport; Communicative styles; Group discussion; Social talk.

\section{Introduction}

Building rapport is one of the goals of communication for people of all cultures. Spencer-Oatey (2000) proposes the framework of rapport management to explain how language is used to promote, maintain, or threaten harmonious social relations. Her theory argues that the motivation for politeness is not the desire to maintain face alone, but also the desire to maintain sociality rights which are fundamental personal and social entitlements that individuals claim for themselves during interaction with others. Since different cultures may have different ideas regarding how rapport should be constructed, misunderstanding and stereotypes are likely to occur in cross cultural communication.

This paper is a comparative study of Japanese and Thai small group discussions which aims to investigate how the speakers of the two cultures manage the equilibrium between task and social emotional areas of their interaction, and how 
rapport is constructed in social talk during the discussions, by examining 'intonation units' or 'idea units' (Chafe 1980, 1994) and attitudinal semantic choices.

Section 2 presents theoretical background of my analysis on cultures and speech styles including some aspects of phaticity in social interaction. Section 3 explains the methodology and data of this study. Section 4 shows three main contrastive features of Japanese and Thai social talk found in this study. Finally, I will summarize the findings by referring to social values perceived to be important in each culture.

\section{Aim and framework}

In this section, I present the background of my research. I review cultures and speech styles in Japan and Thailand in 2.1., "consciousness" and "idea units" by Chafe (1980) in 2.2., politeness and rapport management in 2.3., and phatic communion in 2.4.

\subsection{Different cultures, different styles}

The goal of this study is to show statistically that people of different cultural backgrounds may possess totally different conversational styles with special reference to Japanese and Thai cultures. But how different are they?

Japanese and Thai cultures have often been perceived to be similar in that both are collectivist, hierarchical and belong to Buddhist-based Asian cultures. According to Hofstede's (2003) survey, Japanese and Thai cultures rank high on the collectivist scale, and both peoples give importance to cohesive groups and collective behavior. Furthermore, Hofstede's cultural dimension score shows that Thailand has stronger degree of collectivism than Japan. If culture and language are closely related and influence each other, we should be able to observe their world view reflected in the way they communicate with others in their own cultural groups. However, this is not the case.

Previous studies on conversation style in Japanese (Maynard 1989; Mizutani 1993; Morita 2005, to name but a few) have all demonstrated that Japanese speech styles possesses mutually dependent, harmony-preserving and empathic characteristics. Iwasaki and Horie (1998), upon examining the construction of floor in Japanese and Thai dyadic conversations, found that Japanese use short and frequent backchannels, loop sequences and open floor construction to show their sensitivity and attention towards their interlocutors without being intrusive, whereas Thai speakers display 'infelicitous' topic shifting questions, self-assertive overlap, parallel floor constructing style and few supportive backchannel behaviors, all of which suggest an inclination towards a self-assertive and independent speech style.

Several investigations of communicative styles posit the cultural differences with regard to the extent to which the self is exposed in the encounter (Young 1994; Scollon \& Scollon 2001; Cheng 2003). Barnlund (1975) introduced the terms 'private self' to represent the dimension of self that is known to oneself and not usually shared with others, and 'the public self' to represent the dimension of self that is readily accessible to others. Japanese are postulated to have a larger area of private self which allows less self-revelation when compared to Americans. When people do not share these boundaries of self, they are likely to accidentally intrude into each other's 
psychological territories during interaction.

In fact, a large-scale survey by Wuwongse \& Washiradilok (2001) on the attitudes of Japanese and Thais who had interacted with each other, shows the contrastive attitudes and expectations that people from the two cultures project toward each other. According to the survey, Japanese people view Thais as friendly, fun-loving and group-oriented but also disorderly and self-centered. The Japanese indicated that they expected Thais to be more self-disciplined and respect others' privacy. On the other hand, Thai people view Japanese as serious and obedient to rules, but too formal and guarded in their personal feelings. The Thais expected Japanese to be more relaxed and friendly or ' $k a n$-een' in Thai terminology.

Overall, we may conclude that, despite both countries belonging to collectivist culture groups, Japanese and Thais possess different world views and perception of self in social interaction. The next two subsections provide theoretical frameworks to statistically confirm this intuition.

\subsection{Consciousness in speech production}

Speech behaviors are largely controlled by the cognitive system. According to Chafe (1994), the speakers' mind possesses an internal representation of the larger world in which they are situated. However, a small segment of this information of the world can be active at one time. Chafe calls this 'consciousness', which is the focus of attention at one particular moment. While delivering information, the speaker clings to a center of interest or mental image of what they want to communicate. This is reflected in how people produce speech in a series of brief spurts, or 'idea units' (Chafe 1980). The idea unit is made up of experiences of perceptions and actions including the emotions, opinions, attitudes, desires and decisions of the speaker. It can be identified by intonation contour, pausing, and certain syntactic features. In English, an idea unit usually consists of a single grammatical clause or phrase containing one verb. The unit is often preceded or followed by some kind of pause ranging from a momentary break to one that lasts for several minutes. Each unit expresses what can be seen as a new concept. In Chafe's (1980) 'pear stories' project, participants from different linguistic groups including Japanese and Thai speakers watched a short silent film and recalled what they had seen. The project revealed similar features of idea units produced across all language groups. Chafe suggests that examination of the foci of idea units will shed light on the kind of things that the speaker is interested in during the speech production. For example, they can be used as criteria in examining personal interactions between the speaker and their audience, variable content, process of recalling past stories, perturbations in the expressions and transitions from one center of interest to the next.

\subsection{Politeness and rapport management}

Managing interpersonal relations is often viewed in pragmatics as how human beings successfully use language to avoid face threats, and maintain and build good relationships between speakers and hearers. Brown and Levinson (1987) proposed a theory of politeness which argues for a universal principle of language usage in mitigating face-threatening acts based on the concept of face in human interaction. 
'Face' was defined by Goffman (1972) as "the positive social value a person effectively claims for himself by the line others assume he has taken during a particular contact". Brown and Levinson redefine the notion as two types of desire: Positive face and negative face. The former is one's desire for his or her positive self-image be appreciated and approved while the latter is one's desire for his or her freedom and self-autonomy to not be imposed on by others. They believe that people universally cooperate in maintaining each other's face because of their mutual vulnerability of losing it.

Expanded from Politeness theory, Rapport Management Framework (Spencer-Oatey 2000) takes a broader view by including the building of rapport in other domains besides speech acts which is mainly dealt with in Politeness theory. It involves such domains as discourse, participation and style. In addition to the concept of face, her framework includes the consideration to sociality rights which are fundamental personal/social entitlements that individuals claim for themselves in their interaction with others. In face management, two aspects of human desire that need to be considered are 1) quality face: Our desire to be thought of positively in terms of personal qualities, and 2) identity face: Our desire that our social identities or roles be acknowledged and upheld. Similarly, sociality rights also have two aspects: 1) equity rights: Our right to receive personal consideration and be treated fairly, and 2) association rights: Our entitlement to association or dissociation with others. Sensitivity to any aspect of these four components varies according to the culture.

\subsection{Social talk as phatic communion}

In task oriented group discussion, the activity can cause stress and tension to group members. However, the social emotional side of communication can help alleviate the strain of the activity and keep the equilibrium between task and social relations. Social talk has an important role in facilitating interpersonal relationships and rapport. Despite its low content and propositional meaning, it helps the interactants to find common ground in conversation and helps the interaction proceed smoothly. Malinowski (2006 [1926]) refers to this type of communication as 'phatic communion' which he defines as "a type of speech in which ties of union are created by a mere exchange of words."

Although social talk is a universal phenomenon, its pragmatic usage can be different. Pavlidou's (2000) study shows that Greek and German speakers revealed different preferences in attending to relational aspects in telephone conversations. While Greek speakers tended to show greater amounts of phatic talk at the beginning and ending of conversation, Germans preferred to go straight to the content and finished the conversation using short phrases. Pavlidou's study illustrates that different cultures attend to phaticity of social talk differently. One culture may use small talk to build a relationship during the interaction, but other cultures may attend to the relationship by refraining from small talk.

\section{Data and methodology}

In order to obtain comparable sets of data for analysis, I conducted six experimental discussion groups. Three were groups of Thai speakers, and the other three consisted of 
Japanese speakers. Each group contained five participants who were acquaintances and close in age and academic background. Participants were undergraduate or graduate students between the ages of 19-35 who were members of some circles in their universities. The topic of discussion was a problem-solving situation that required the group to reach a consensus. The scenario was an accident scene in which they could only rescue three people out of ten survivors. Participants discussed the scenario in their native language. All discussions were recorded and transcribed. Utterances were segmented into idea units (Chafe 1980), which were then labeled and classified according to the actual communicative function. The classification is broadly derived from the seminal work of Bales (1976) for assessing patterns of small group analysis. However, it is different from Bales' Interaction Process Analysis (IPA) in that, firstly, the categories of idea units in this study were set up on the basis of functions that actually appeared in the data, instead of using categories established a priori. Secondly, the calculation is based on Chafe's idea units, not the IPA units which are mainly the single simple sentences expressing a complete thought. This is because the linguistic systems of Thai and Japanese are too different to compare their spoken language quantitatively by any other units than the idea units that allow representation of the speaker's consciousness across cultures. In this study the idea units were identified primarily by: 1) intonation contour appearing as a clause-final signal; 2) single identifiable item of concept; 3 ) brief and long pauses that occur before and after the unit.

All idea units were sorted into 9 categories, one of which is 'social talk' which is the focus of this paper. For the purposes of this study, social talk is defined as utterances that are not directly concerned with the task of solving the problem but have significance in framing the interpersonal relationships of the group. It includes non-task comments, playful remarks, apologies, showing solidarity, and disclosing one's attitudes and feelings. It does not include back-channels, exclamations, and laughter. Table 1 shows the summary and proportion of Social talk that occurred in each group.

\begin{tabular}{|l|c|c|c|c|c|c|}
\hline \multirow{2}{*}{} & \multicolumn{3}{|c|}{ Japanese groups } & \multicolumn{3}{c|}{ Thai groups } \\
\cline { 2 - 7 } & JA & JB & JC & TA & TB & TC \\
\hline Time spent (minutes) & 25 & 53 & 37 & 16 & 41 & 41 \\
\hline Total idea units & 1100 & 1974 & 1699 & 725 & 1661 & 2283 \\
\hline Idea units of social talk & 34 & 130 & 238 & 38 & 299 & 196 \\
\hline $\begin{array}{l}\text { Percentage of social talk in } \\
\text { group discussion }\end{array}$ & $3.09 \%$ & $6.59 \%$ & $14.01 \%$ & $5.24 \%$ & $18.00 \%$ & $8.59 \%$ \\
\hline
\end{tabular}

Table 1 Summary of the social talk amount and idea units in all discussion groups

Upon examining the speech data of the two cultural groups, what stands out is how differently the speakers of the two cultures aimed their focus of attention, and the language they chose to express themselves and their attitudes. These two aspects will be the index I adopt in this paper as guidelines for exploration.

Index 1: Focus of consciousness

Focus of consciousness in the idea unit is what the speaker is most conscious of at the moment of speaking. It is identical to 'Topic' or 'Theme of the clause' in Systemic Functional Grammar which refers to the psychological subject or concerns of the message. It serves as a point where the new information starts and indicates what the sentences will be about (Halliday 1985). Japanese and Thai are similar in that both are 
topic-prominent languages where word order is dependent on information structure. In a long discourse, one topic may go across several speech units. In such case upon assessing the topic frequency, a topic is counted as one until the shift is observed in topics or speakers.

In examining the topics of the utterances, the present study classifies topics into two categories: Individual oriented topics and Communal oriented topics. The former are topics concerning individual persons present in the group. They include personal experiences or personal knowledge of the speakers themselves, or those of the hearers, including messages directed to individual members in particular. The focus of messages in this category can be further divided into two subcategories: a) whether the topic is about the speaker him or herself (self-focused topic) or; b) whether the topic is about one of the hearers in the group (hearer-focused topic).

Communal oriented topics are topics concerning common knowledge and shared experiences of group members overall. They may be non-task comments regarding the situation the group was facing, attitudes towards the task they were handling, and knowledge that everyone in group shares in general.

Index 2: Semantics of attitudinal encoding

Semantic choices can exhibit interactants' attitudes towards each other and towards the world. In casual talk, they are important devices for constructing and signaling degree of solidarity and intimacy in relationship (Eggins and Slade 1997). As for the evaluative device in this assessment, I looked at features of how speakers graded their attitude in their social talk production; whether they added or reduced the degree of strength of their remarks and in what manner. Linguistic elements that add emphasis to the meanings are classified as intensifying devices ('intensifiers'). Elements that serve to weaken the intensity and urgency of the utterances are classified as softening devices ('softeners' or 'hedges').

\section{Analysis}

The analysis reveals three major differences between Japanese and Thais. First, Japanese participants build common ground through their discussion of communal topics rather than topics of individuals. While Japanese participants prefer to direct attention to the overall state of being and generality of topics, Thai participants show inclination toward particularity of events and prefer the Individual-oriented style of talk. Second, Japanese show a preference for softening their speech rather than intensifying it, and using conventional expressions rather than newly created unconventional ones. However, Thai speakers prefer to use intensifiers and spontaneous expressions to show involvement and create a fun atmosphere in their interactions. Third, Japanese speakers prefer to minimize the prominence of self and display dependence of self on the group as means of constructing group rapport, whereas Thais show no inhibition in maximizing the sense of self and prefer to construct group rapport from personal relationships. In the rest of this section, I will present the differences in the characteristics of foci of consciousness between Japanese and Thai social talk. 


\subsection{Characteristics of social talk in Japanese group discussions}

\subsubsection{Preference of using Communal oriented topics to Individual oriented topics}

Japanese participants showed a preference to build common ground through social talk based on communal concerns rather than personal concerns. Communal oriented topics concerned issues or information that a majority of group members shared, for example the task, group or the situation that they were in. All Japanese groups show consistent patterns; Communal oriented topics occur in more frequency than Individual oriented topics, and more self-focused topics occur than hearer-focused ones, as shown in Table 2.

\begin{tabular}{|l|cc|c|}
\hline Groups & \multicolumn{2}{|c|}{$\begin{array}{c}\text { Individual oriented topics } \\
\text { (self-focused }: \text { hearer-focused) }\end{array}$} & Communal oriented topics \\
\hline JA & 5 & $(5: 0)$ & 19 \\
\hline JB & 20 & $(10: 10)$ & 69 \\
\hline JC & 65 & $(44: 21)$ & 126 \\
\hline
\end{tabular}

Table 2 Proportion of topics occurred as foci of consciousness in Japanese groups

Japanese participants showed a strong tendency to build common ground through social talk based on general comments that were easy to agree with. Most evaluative remarks expressing a speaker's empathic concerns and attitudes toward states of beings in the shared context such as taihen 'terrible', omoshiroi 'interesting', muzukashî 'difficult', kawaisōni 'pitiful', sugoi 'superb', often induce shared feelings and solicited general acknowledgement from hearers. Examples of these types of remarks are;
a. $\quad m \bar{a}$, demo omoshiroi ne.
b. chotto muzukashii.
'Well, but that's interesting, isn't it?'
c. taihen sōjan.
'It's a bit difficult.'
'It looks difficult, doesn't it?'

Due to the nature of Japanese collaborative speech styles (Mizutani 1993; Iwasaki \& Horie 1998), general arguments make it easier for members to acknowledge or accept the mood of the earlier speaker, creating an echo effect. Consequently, it gives the impression of Japanese social talk as being agreeable and placid in style. Excerpt 1 is an example of how participants carry on their discussion collaboratively. In this excerpt, members make fun of their logic of discarding a man in an accident scene.

\section{Excerpt 1 (Group JB)}

1 JF9: @ sugoine. @

2 JF10:@ kitanakunattekita hanashi.

3 JM6:

4. JM7:@kitanai hanashi. [@

5 JM8: [a

6 JA9: [@]

$7 \quad$ JA9: kitanakunattekita hanashi.@

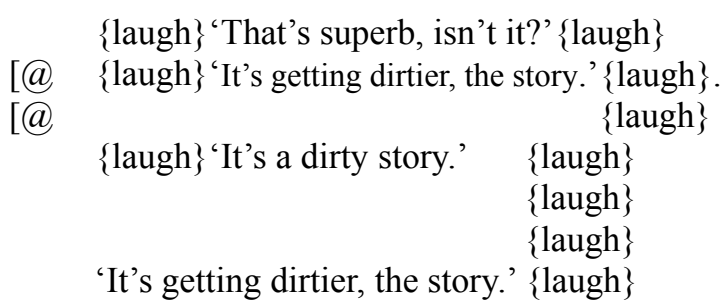

In excerpt 1 , before the first line, JM8 and JM6 were discussing whether they should leave the pilot at the accident scene, as the pilot might have a life insurance which 
ensured a big payout in case of his death. JF9 laughs and comments that the logic sounds superb. Her comment makes other participants (JM6, JM7, JM8, JF10) laugh and take turns in making similar comments. Speech sequences like this are often observed in this study and are common in Japanese daily casual conversation.

What is illustrated can be seen as a reflection of Japanese consciousness in social interaction regarding ' $w a$ ' or overall harmony. In the $w a$ concept, individuals should not stand out and any conflict of views is avoided. Ide (2006) has pointed out that wakimae (discernment of social context) guides Japanese people to adjust their behaviors to suit context. In other words, polite behavior arises from the context that determines how one should talk, behave and participate in the ongoing situation.

Wakimae is expressed not only by honorifics, but also by showing one's awareness toward the appropriate amount one is to contribute in certain topics of talk, as we will see later. The amount of speech that each Japanese and Thai member made in their groups suggests that Japanese members took pains not to intrude association rights of others in the interaction. This participatory style is uniform across three Japanese groups.

In a group discussion, where accomplishing a communal task is the main concern, Japanese displayed their attention toward communal matters and invested themselves in building group cohesion rather than individually specific interest. Therefore, non-task topics focusing on personal matters of the individuals are kept at minimum. The concept of $w a$ is also seen in the way one shows coherency and linkage to a prior speaker's statement. Speakers show coherency in conversation by giving a constant flow of various supportive tokens (Iwasaki \& Horie 1998). As seen in this study, speakers repeated each other's Communal-oriented social emotional remarks before switching to a new topic. The Communal oriented topics make it easy for members to construct a sense of harmony.

\subsubsection{Preference of softeners/hedges and familiar expressions}

Softeners and intensifiers are both crucial devices in rapport management. Softeners play an important role in reducing the risk of face threat in speech, and therefore are devices in the attainment of smooth interaction. On the other hand, intensifiers play a role of signaling degrees of involvement in the interaction and intimacy in relationships. In casual talk among close friends, where the situation welcomes a high degree of involvement and poses low risk of face threat, it would be expected to find more intensifiers than softeners. However, even in such a situation, Japanese participants use many more softeners than intensifiers.

Table 3 illustrates frequency of softeners and intensifiers used in the three Japanese groups. It shows a consistent pattern in all groups: softeners noticeably outnumber intensifiers. The table also includes the final particle usage since the softening effect in Japanese spoken language is greatly represented by final particles. According to Uyeno (1971), the sentence particle $n e$ and its variants $(n \bar{e}, n a$, and $n \bar{a})$ indicate a speaker's intention not to make an imposition on the hearers and adds a softening effect to the sentence. She calls these types of particles 'particles of rapport'. The present study found that 54 out of 71 final particles $(77 \%)$ used by all three Japanese groups had the softening effect. These particles are ne (22 times), yo ne and $d a$ $n e$ (20 times), na (11 times), $k a$ (once). Taking these particles into account, the 
proportion between total softeners and intensifiers is $146: 31$ in ratio.

\begin{tabular}{|l|c|c|c|cc|}
\hline Groups & Idea units of social talk & Softeners & Intensifiers & Final particles (softening effect) \\
\hline JA & 34 & 9 & 5 & 11 & $(7)$ \\
\hline JB & 130 & 37 & 7 & 30 & $(29)$ \\
\hline JC & 238 & 46 & 19 & 30 & $(18)$ \\
\hline Total & 402 & 92 & 31 & 71 & $(54)$ \\
\hline
\end{tabular}

Table 3 Frequency of softeners and intensifiers in Japanese groups

Softening devices are particularly crucial when the message is directed to or about the hearer (hearer-focused). Although the participants in this study are close friends, their speech still employed various kinds of and a great number of softeners/hedges. Of 25 hearer-focused idea units in three Japanese groups, twenty tokens of softeners (not including non-verbal clues) were observed. Example (2) illustrates hearer-focused idea units where softening devices are underlined. They are particles and phrases such as nanka 'sort of', mitai 'like', chotto 'a little', sōna 'likely', and ki ga suru 'feel', interrogative sentence structure such as jan 'isn't it?', desu ka 'isn't it?', and janai $n$ desu ka 'isn't it?', and final particles ne 'don't you think?' that produce a softening effect.
a. nanka jinmon mitai.@
b. iesōna kigasuru.@.,
c. damejan.
d. danzen desu ka?
e. sugoku tanjun janai $n$ desu ka?
f. chotto chigaune@,

\author{
'You are sort of cross examining us.' $\{$ laugh $\}$ \\ 'I feel that you can say it.' \{laugh\} \\ 'You weren't supposed to.' \\ 'You mean (your decisions were) absolute?' \\ 'Isn't your answer too simple?' \\ '(Yours are) a bit wrong, I think.' \{laugh\}
}

Hedges have been regarded as a negative politeness strategy (Brown \& Levinson 1987), and used widely in managing conflict (Honda 2002). Despite the fact that social talk is meant to build interactants' solidarity and is considered a positive politeness strategy in larger frames, interaction of the sentence level in Japanese groups is permeated with negative politeness strategy.

It is also worth noting that no hearer-focused message found in this study occurred on its own by the speaker's initiation. All of them were responses to some earlier utterances. For example, (2a) is a response to a question "Why didn't you choose C?" The reason that Japanese participants avoid initiating hearer-focused topic during task discussion, and limit themselves to saying it simply as a follow-up response is probably because raising someone as the focus of attention in a situation where achieving task is a common goal could risk intruding in his/her sociality rights. These rights involve the ways in which individuals manage themselves to fit the social expectancies. Since $w a$ and wakimae is what is expected in social interaction, participants show considerations to each other by avoiding initiating hearer-focused topics and by adhering to building common ground on the safe zone of the public sphere.

As for intensifiers, which are sparingly used in Japanese conversation, the 
adjective sugoi 'superb' and its variant sugoku 'superbly' amounts to nearly half of them. Sogoi/sugoku appeared 14 times out of 31 intensifiers, or $45 \%$. Examples of other intensifiers are $k e k k \bar{o}$ 'fairly' appearing 3 times (9\%) and yappari 'just as I thought' 2 times $(6 \%)$. Intensifiers used in Japanese groups are largely modifiers of general comments. Most of which concern states of things and beings, for example muzukashi 'difficult' (appearing 25 times), taihen 'terribly' (5 times) and omoshiroi 'interesting' (5 times). Compared to intensifying devices in the Thai groups, Japanese intensifiers are less in number, varieties, forms and usage. The lack of variety in intensifiers and frequent use of general and similar comments show the preference of the Japanese to use familiar and conventional expressions.

Intensification of language in social talk can signal the degree of intimacy and involvement. It can also be done by using colorful words and phrases instead of neutral ones, using vocative, jargon or in-group words, swearing, and so forth (Eggins and Slade 1987). From the entire Japanese speech data, however, only one usage of derogatory language occurred; kusobōzu toka iwanai yone 'We are not going to call him a bastard monk, are we?' Although intensifiers are used to add strength to expressions, they are often cancelled out by some forms of softeners. So the intensifiers seldom function fully to their strength. The excerpt below illustrates this point. In this excerpt, participants are expressing their mixed feelings about the choice they are to make. Intensifiers and softeners appear concurrently. Intensifiers are illustrated in bold letters, and the softeners are underlined.

Excerpt 2 (Group JB )

1 JF9: ichiban nayamu toko da yo ne, koko 'The most difficult part, isn't it, this point?'

2 JM7: a:: muzukashīna:

3 JF10: $n::$ ichiō kimeta kedo.

4 JM7: un ma: sorenari ni bimyō na.

5 JF10: un (..) kore kana ichiban iino yappari.

6 JM8: un (..) kimeta

7 JF9: watashi mo kimeta (..)

8 JF9: demo chotto kekk̄ jibun tekini nattoku ikanaikedo@,

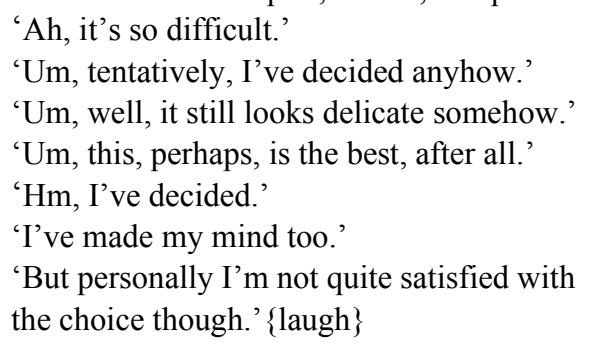

In the beginning, JF9 expresses her uneasiness and emphasizes her feeling by using an intensifier ichiban 'the most'. However, she finishes her statement with yo ne which functions to elicit the shared feeling from others. Other participants also express their feelings in the same mood; that is, they feel uneasy but yet have made up their mind. Each one marks his/her utterance with some sorts of softeners; JM7 lengthens the sound of $n a$ in line 2, JF10 uses the word $i c h i \bar{o}$ 'tentatively' finishing her utterance with kedo 'though' in line 3, and in JM7's line 4 appeared the word sorenari 'in its own way' with his comment unfinished. At the end of the excerpt, JF9 says she is still to be satisfied at the choice of solution, using the word kekkō 'fairly' to amplify her feeling of dissatisfaction, but glossing it over by several mitigating devices such as chotto 'a little bit', jibun tekini 'personally', kedo 'though' and laughter.

Softening devices and preference for familiar expressions can be seen as an instrument for reducing the risk of accidental exposure or encroachment upon each other's private self. Japanese culture encourages people not to show strong emotions or use overt expressions, and to maintain neutral or mildly positive expressions (Brosnahan 1990; Hasada 2006). Strongly expressed emotions, whether they are 
negative or positive, can provoke disturbance in the minds of others. Lebra (1976) concludes that the effect of Japanese language must be controlled, subdued, circumscribed, or diluted because it is the social relationship that counts, not an individual's emotion.

\subsubsection{Self-minimization as means of rapport construction}

Of all Individual-oriented topics in Japanese discussions, topics that are focused on speakers' selves occurred more than the hearer-focused ones. Upon examining the content of self-focused expressions, the content is largely concerned with speakers' inadequacy, uncertainty and worries about their task performance. For example, words and phrases that appeared frequently were doshiyo 'what shall I do?', nayamu 'to worry' and mayou 'to be at lost'. They often co-occur with speakers' statements of opinion. Below are examples of self-mentioning remarks which contain this type of message.

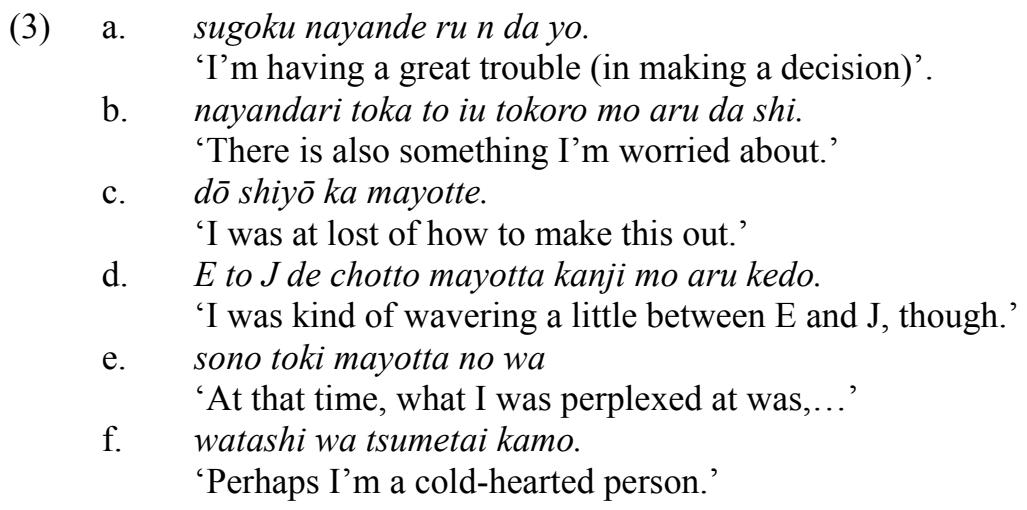

Speakers in this study minimized themselves by telling the group members that they are worried and perplexed during their thinking process, yet they have been working very hard and seriously in coming up with the answer. Simply showing seriousness and caution in one's talk is not a practice to be appreciated in Japanese interaction. Self-effacing expressions can be seen as self-presentation tactic designed to convey to others that one is modest. It helps to enhance the likeability and rapport in Japanese interaction.

Self-focused remarks are, by definition, the remarks focusing on the speakers' selves. However, this type of remark in this study is closely related to the concern for task operation and/or group interest. For example, when speakers noticed that their performances delayed the progress in discussion, or they affected the group in an unfavorable way, they tended to voice their concerns mitigating their statements with modality expressions or laughter, and in some cases apologized to the participants. Examples of these statements are shown below.
(4) a. atashi dake? moshikashite.
'Is it only me perhaps (who haven't decided yet)?'
b. saigo datta.@
c. ore ga machigatta.
'I came the last.' $\{$ laugh $\}$
'I made a mistake.'
d.@gomen ore kanchigai shita.
\{laugh \} 'Sorry, I misunderstood it.' 
Self minimizing does not necessarily equate with low esteem, but it can be understood as a manifestation of interdependent values of Japanese culture. Members of interdependent culture are acculturated to see themselves as part of an encompassing social relationship associating with the group (Markus and Kitayama 1991). In the case of Japan where $w a$ is the cultural ideology, minimizing oneself is regarded as a tactic in building rapport with others in groups and in general interaction.

\subsubsection{A summary of Japanese group discussions}

This section has demonstrated three characteristics of Japanese group social talk that occurred during discussion. First, Japanese participants preferred to build common ground through their talk on communal topics that the majority of group shared. Rapport management in Japanese groups deals with the comprehensiveness and the orderliness of the situation. The appropriate amount of talk, the role one is to take and the appropriate topics on which common ground is built upon is pre-determined in the context. Participants maintain rapport by behaving in accordance with those tacit pre-determined rules.

Second, Japanese participants show a preference for using softening devices rather than intensifying language, and conventionalized expressions rather than newly created unconventional ones. Rapport construction in Japanese interaction gives more importance to sociality rights than individual face.

Third, Japanese speakers show the minimization of self as a means to form rapport. Self-minimization in social talk helps to mollify the speaker's opinions and show the speaker's prudence. Its content shows how the speakers see themselves in relation to the communal task or the majority of others in group. Despite being self-focused, the statements demonstrate much relevancy between the self and the collectivity.

In the next section, I will show the opposite characteristics of social talk in three Thai group discussions.

\subsection{Characteristics of social talk in Thai group discussions}

\subsubsection{Inclination toward Individual-oriented nature}

Thai groups do not display clear or consistent patterns whether the topics are more oriented toward communal concerns or personal concerns. However, there is the tendency of Thai groups to present individualistic interaction. Table 4 shows the frequency of Individual oriented topics versus Communal oriented topics, and self-focused topics versus hearer-focused topics in comparison.

\begin{tabular}{|l|c|c|}
\hline Groups & $\begin{array}{c}\text { Individual oriented topics } \\
\text { (self-focused }: \text { hearer-focused) }\end{array}$ & Communal oriented topics \\
\hline TA & $25(9: 14)$ & 10 \\
\hline TB & $103(44: 59)$ & 114 \\
\hline TC & $75(50: 25)$ & 81 \\
\hline
\end{tabular}

Table 4 Type of topics occurred as focuses of consciousness in Thai groups 
Table 4 shows that common ground in Group TA was built more on Individual oriented topics, while in Group TB and TC it was built more on Communal oriented topics. However, it must be noted that Group TB and TC had a strong individual flavour in that most of the discussion (45.82\% in Group TB and $40.56 \%$ in Group TC) was dominated by the group leader alone. The leaders of these two groups also contributed a greater proportion of the Social talk category as well. The leader of Group TB contributed $71.57 \%$ and the leader of Group TC $43.87 \%$ of the Social talk in their groups.

Unlike the Japanese groups, the Thai groups did not show clear signs that efforts were made to manage an equitable amount of discussion among members. While the highest proportion of talk that an individual member in each Japanese group made falls within the close range $(30.19 \%, 30.55 \%$ and $32.73 \%)$, the highest percentage of talk an individual member in Thai groups made was $27.72 \%, 40.56 \%$ and $45.82 \%$ with group leaders being the persons who assert themselves the most in both task and social emotional areas of the activity. This tendency suggests an all-inclusive participatory style of Thai leaders in interaction. The fact that certain members exert themselves in greater length than others tells us that there is lesser approximation of one's speech amount and less observing to association rights among members in Thai groups. The greater range of numbers across three groups implies lesser conformity of interactional styles.

As to whether the topics are focused more or less on the speaker-self or the hearer-self, there seems to be no difference. No group showed significantly similar patterns. The self of the speaker and of the hearers are freely picked up as topics, suggesting the free participatory style of Thai groups. In order to compare the characteristics of Japanese and Thai communal topics, I will illustrate Thai Communal oriented topics in this subsection, and will discuss the features of Thai Individual-oriented topics later.

Thai idea units, despite being built on communal common ground, were directed to particular events such as individual actions, and they were less likely general comments. Some examples of Communal oriented topics in Thai groups are given in Examples 5-7. Many words were used to depict dynamism and intensity of the actions, such as kliat 'hate', taai 'die', chûai châat 'serve the nation', nui 'cut and run', thín 'dispose' and so forth. Such words carry attitudes and added feelings to speech since speakers could have used other neutral words in those contexts, however they chose the more colorful ones for the effects. Some utterances are upgraded and animated by expressions such as atamaa and yoom (the highly specialized first and second person pronoun used by Thai priests to laypeople or subordinate monks), thŭg kèckam 'die' (exaggeratedly official word) in Example (5). Some mimic the sound of the fictitious characters in the task, for example, the manner and sound in which the handicapped person may perform in their work at the factory, or of the grief of the mother who lost a child in the accident. Sometimes derogatory words were used such as man (a pronoun literally meaning 'it', normally used for inanimate things and animals but also to refer to humans in a derogatory sense) as in Example (6), whereas in some instances kinship terms were employed to show emphasis and intimacy as phî 'sister' used as vocative, and luy 'uncle' used in Examples (6) and (7). The latter term refers to the entrepreneur who is one character in the task, so that the speaker put life in the fictitious character making him seem more real. 
(5)
a. thîy atamaa wái thîinîi tho
b. ar yoom tháylăai con \{praying gesture\}

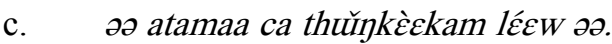

(6) a. man taai phîi.

'They will die, you guys (older siblings)'.

b. phiii, khon thîi phîi lûâk toonnîi nîa, khuuu man taai pai léEW.

'Sister, the guys you are choosing now, (you can think of them as) dead men.'

c. lư tồn chûai châat.

'The uncle must serve the nation.'

Interestingly, some exploited knowledge exclusive only to in-groups, as seen in Example (7), the speaker speculated that the university professor, a character in the task, was the one that everyone hated and therefore likely to be left out from their choices. What the speaker said was an ironic joke made on the assumption that the members shared antagonism against professors.

aacaan mahăalai mii tèc khon klìat châimái nîi.

'The university professor, everyone just hates him, right?'

The shared assumption is also observed in the expression chûai châat 'be of service to the nation' in (6c) which connotes the Thai nationalism slogan often used to invoke patriotism. What the speaker meant was that the entrepreneur must serve the nation by making sacrifice to the group. Both remarks could only be understood by those who shared long history of experience in the same social circle. Communal common ground in Thai groups shows relatively high degree of specificness, inclusivism, and particularity of events, implying the inclination toward individualistic nature of talk.

\subsubsection{Preference of spontaneous and emphatic expressions}

While Japanese show a preference for using softeners and familiar expressions, Thais show the opposite characteristic. Thai social talk employs intensifiers and spontaneously created language much more than hedges and conventional expressions. Speakers do so by several means of language intensification, for example by using intensifying modifiers, final particles, colorful phrases, animating fictitious characters, repeating sounds, name-calling and emotive interjection. Table 5 summarizes the occurrence of intensifiers and softeners found in each of the Thai groups. Final particles are shown as references due to the fact that they are also tools used in adding or reducing strength to the statement. Similar to Japanese final particles, Thai final particles are used to indicate stance and personal feelings towards the information spoken. However unlike Japanese, most of Thai particles have the functions of emphasizing, confirming, directing hearers' attention. Since the numbers of intensifiers are obviously higher than softeners and it is difficult to determine whether a particle is an intensifier or softener, this paper set aside these particles. 
Table 5 Frequency of softeners and intensifiers in Thai group social talk

\begin{tabular}{|l|c|c|c|c|}
\hline Groups & Idea units of social talk & Softeners & Intensifiers & Final particles \\
\hline TA & 34 & 3 & 16 & 8 \\
\hline TB & 287 & 8 & 54 & 37 \\
\hline TC & 194 & 7 & 59 & 54 \\
\hline Total & 484 & 18 & 129 & 99 \\
\hline
\end{tabular}

The study found that intensification in Thai interaction occurred in greater number and variation than that in Japanese groups. Below are examples of intensified utterance units in Thai social talk. Intensified expressions are illustrated in bold letters

(8) a. phî̀ luâak khâa khon na nîa toon nîa

'Sister, you are choosing to kill now, you know?'

b. khшuш khuшu rao pen phrá câo nâ phîi

'That is, that is, we are God, sister.'

c. tii thúk khon taai ŏo::

'You intend to hit everyone to death, oh.'

d. lûk hăai pai năi lûk hăai pai năi

• 'Where's my child gone? Where's my child gone?'

In (8a), the speaker commented emphatically that choosing people according to the instruction meant choosing people to kill. He emphasized the statement by using a metaphorically strong word khâa 'kill, murder' to denote an act of choosing a person, and by using final particles na nîa, and the word toon nîa. 'now' to emphasize his utterance.

The speaker in (8b) compared participants in the discussion to God for having a power to decide who lives or dies. By using a powerful word phrá câo 'God', he generated an intensifying effect to his statement, and by the final particle $n \hat{a}$ together with kinship term vocative $p h \hat{\imath} i$ 'sister', he created a family-like affinity with the hearer.

In $(8 \mathrm{c})$, the speaker repeated the strong words tii 'hit', taai 'die' used by the previous female speaker who said it without hedges. He showed his attention by repeating her line and added the emotive interjection $\check{o}$ :: to emphasize his feeling of awe.

Sometimes, speakers put life in the story by talking as if they were characters in the task or by making sound or movement of the imaginary activity. An example is (8d), where the speaker acted the part of the mother who lost her daughter.

Intensified and spontaneous expressions are closely associated with the 'high-involvement' conversational style (Tannen 1984). Speakers with this speech style respond quickly, shift topics abruptly, talk at fast speed, are animated, and use personal topics. These characteristics are shared by what Iwasaki and Horie (1998) call 'self-assertive speech style' - a style found in their study of Thai dyadic conversations. In this speech style, speakers control the conversation by shifting topics infelicitously, 
constructing the conversation floor in parallel, and overlapping intrusively. It is not uncommon to see several participants talk simultaneously colliding head-on over their contradictory stance. The following is an example in which intensifiers are in bold letters.

\section{Excerpt 3 (Group TC)}

1 TM14: $\boldsymbol{m a n} \underline{\underline{\text { taai }} p h i ̂ i,}$

2 TF15:@

3 TM14: phîi, khon thîi phîi luâak toon

$4 \quad$ nîi nîa, khuu man taai pai léeW

5 TM13: man mâi taai kôs [dâai

6 TM12:

7 TM14:

8 TM12: [mûân nai năy ná

9 TM13: [man mâi taai

10 TM14: [man ca taai

11 TM13: man mâi taai, man mâi taai

12 TM14: əə nîa, man ca taai léew

13 TM14: phii luâak khâa khon na nîa toon nîa@
'They will die, you guys.'

\{laugh\}

'You know, the guy you are choosing, they will die for sure.'

'He might not die.'

[mû̂an nai năy, mû̂an nai năy

'This is like a movie, like a movie.'

'He will die.'

'Like a movie.'

'He won't die.'

'He will die.'

'He won't die, he won't die.'

'Well, this, he is going to die.'

'Brothers and Sister, you choose to kill a man now, you know? \{laugh\}

In the excerpt above, TM14, who is almost the youngest in the group and acts as an emergent leader, first says that the three people that they will choose to leave at the accident scene will die without question. The proposition is definitely pronounced, without a probability modality. Every word he uses - man taai phịi (line 1) connotes emphatic attitude. Man, as previously mentioned, is perceived as a slightly derogatory term. Moreover, the word taai 'die' which carries a strong meaning is not modalized, and is stressed. The word phîi 'older sibling', which is a kinship term used in fictitious sense, is added at the end of his utterance to emphasize the speaker's point. TM14 even continues emphasizing in the next turn (lines 3,4 ) by repeating the statement with more intensifiers (toon nîa, nîa, pai lécW).

Self-repetition signifies the speaker's intensifying feeling. It is a conversational strategy Kumagai (2004) calls "express of emotions" and "intensification of speech acts". This strategy is used frequently by several speakers found in Thai data. For example, in most of the TM14's lines, the speaker uses the strategy to hold a floor and his stance, and as a rhetorical device to add emphasis to his playful comment. TM13 and TM12 also use this strategy (lines 5, 9, 11 and 6,8). Moreover, there were quite a number of interruptions. For example, just as TM13 (lines 5) expresses his disagreement to TM14, TM12 interrupts with a new topic (line 6) which shows no coherence in the sequence. Just when TM13 is finishing his remark and TM 12 is starting a new message, TM14 simultaneously continues to express his disagreement (line 7). Then in the next turn, three speakers (lines 8-10) interject simultaneously the points they made earlier; TM12 says it is like a movie, TM 13 says the people would not die, and TM14 says the people would die. TM13 and TM14 continue repeating themselves until TM14 laughs.

The use of intensification in Thai language is omnipresent. A contrastive study of 
English and Thai by the U.S. Defense Language Institute (Lekawatana 1974) states that Thai contains a great many intensifiers, compared to English. Several studies on Thai media point out that even newspaper or public media especially when reporting crimes are filled with emotion-ridden and strong language usage (Witthayasakphan 2009). It even reaches the point of severity (Media Monitor 2009; National News Bureau 2009). The finding of this study substantiates this argument. It reflects the general public's preference of using emphasized language to create emotional involvement and dynamic interaction.

\subsubsection{Assertion of individuality as tool for rapport construction}

The ratio between self-focused and hearer-focused topics in Thai groups does not show a consistent pattern as in the Japanese groups. There is no significant difference between speakers raising themselves or the hearers, as the topic of the message indicating the flexibility in projecting the self in social group. It is not clear whether it is the speaker's self or the hearer's self. Speakers show no inhibition in asserting oneself over others. Example 9 shows this type of self-focused message. When speakers talk about themselves, the content tends to touch upon the relations between the speakers and other participants. They are, for example, self-focused remarks expressing like-mindedness, similar personal traits, shared past episodes, shared acquaintances, and so forth between the speakers and the hearers. Furthermore, intensifiers are often used to strengthen their relations. In the example below they are identified in bold letters.

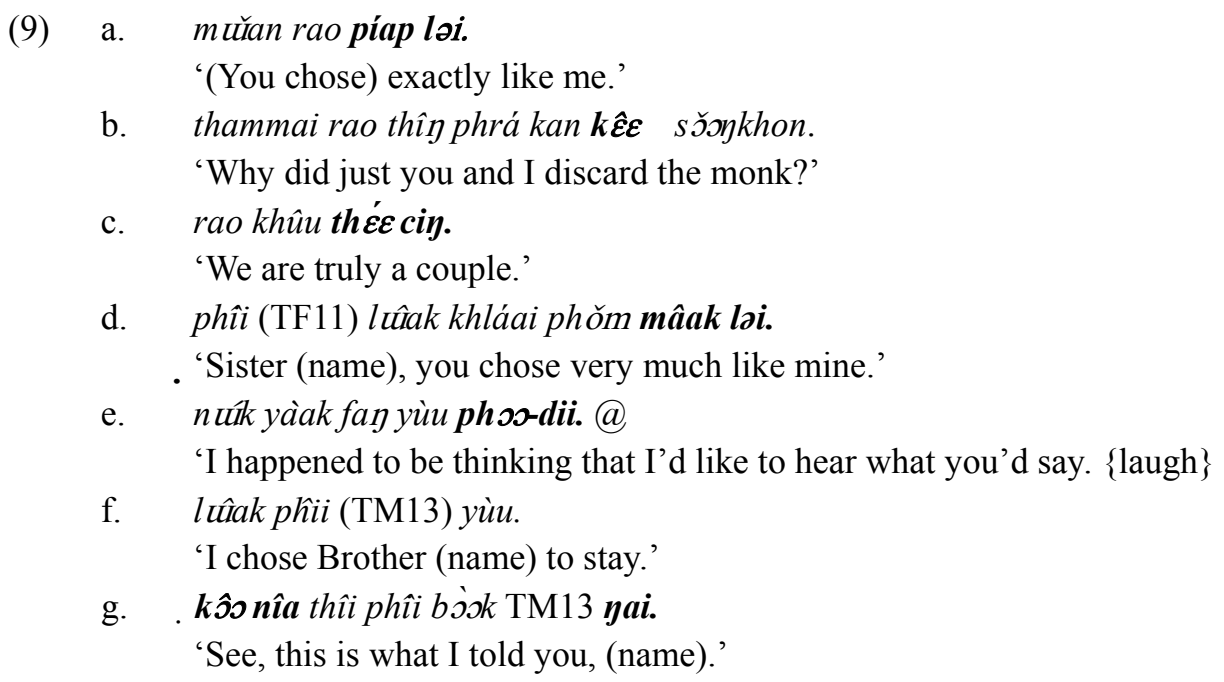

In (9a,b,c,d), each speaker expresses how s/he and the hearers are alike with respect to their choices and their personal traits. More often than not, speakers use intensifiers to emphasize the statements, hence strengthening engagement with the hearers. In (9e), the speaker expressed her interest to a particular individual. In (9f), the speaker equated a participant with a character in the task whom he felt for and would choose to save. In $(9 \mathrm{~g})$, the speaker referred to the exclusive experience that he and one of the hearers shared at the earlier stage. These examples show that self-mentioned topics in Thai social talk differ greatly from those of Japanese. While Japanese subdue the sense of 
self and refrain from bringing up the other individual as the topic, the self of individuals in Thai groups is asserted, highlighted and employed fully as basis for rapport construction.

Hearer-focused topics are initiated more freely and spontaneously in Thai than in Japanese group discussions. Thai speakers are not reluctant to take up other individuals as topics of social talk during task discussion in order to relate one member to the other member(s) in group. In other words, hearer-focused topics in Thai group talk often function as the mechanism in building rapport among members. Examples in (10) demonstrate this.
a. и́u:: soulmate.
'Wow, (you guys are) soul mates.'
b. aria nò i man ká baias lécw.
'He's ready to show bias on even a small matter.'
c. nîa lè khráp khwaam khît dèk aayú yîisìp š̌oy
'This is a twenty-two-year-old boy's thinking.'
d. khon thîiphîi (TF11) thîng khшuш phûuchaai@
'The ones you/sister (TF11) chose to discard were men.' \{laugh

In (10a), the speaker made fun of two group members who were talking about how similar their choices were, and teased that they were soul mates, emphasizing her feeling by emotive interjection.

In $(10 \mathrm{~b}, \mathrm{c})$, the speaker made fun of the youngest participant of the group, by giving a negative account of his decision in a joking manner. This disparagement can be understood as an attempt to mitigate the group's opinion on the junior, who the speaker paired up with in the discussion. Both were from the same department, the only male members of the groups, and younger than all the females in the group. Since the speaker was more senior and took the role of leader in this discussion, he took the younger male under his wing. He belittled him with the sole purpose of making the junior to fit in the group and of creating solidarity.

In a similar vein, the speaker in (10d) spoke for TF11, the eldest female member, by making a teasing remark followed by laughter that she discarded all men. All members shared the knowledge that TF11 was well beyond her marriage age but still single. According to Straehle (1993), teasing is a form of humor or play that can signal and enhance speaker enjoyment and rapport, but it is perceived as distinguished from being hostile because it is conveyed through the interactive frame which participants share. In this study, the interactive frame is signaled as 'play' by various contextualization cues. According to Gumperz (1982), these cues include features such as prosodic phenomena, lexical and syntactic options, and formulaic expressions. In this case the remark was but immediately followed by the speaker's laughter. Besides this cue, early on and throughout this discussion, such discourse features as playful lexical choices, exaggerated intonation, marked pronoun used, overlapped, and repetition have operated to frame utterances as teasing and to reveal aspects of the participants' relationships.

Smaller frames can be embedded in to construct a larger frame. Several instances of colorful language usage, intensifying devices, and the casual mode of speaking in Thai groups have framed a speech situation as non-serious, light-hearted and allow room for more play. There are some occurrences of Thai speakers focusing on 
themselves in an exaggerating manner to preempt the disagreement from group. The speakers in Example 11 give negative accounts of themselves in order to rationalize their actions. Exaggerated expressions signal their awareness to what the hearers might perceive of them, hence reduces assertiveness in their remark for building rapport with the hearers.
a. rao mâi khôi yoom fay khon ùum ná
'I am the type of people who seldom listen to others', right?'

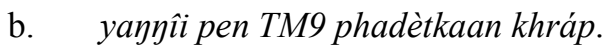
'This is called-TM9: the dictator'
c. pen phûak mâi khôi mii aria yéż ná
'I am the kind of people who seldom disagree with others, right?'

In the examples above, TM 9 who is the speaker of sentences (a) and (b) and the leader of Group TB, calls himself with exaggeration an autocratic leader. Playfully he did so after a long sequence of trying to make his group come down to one decision. By blaming himself for his dictatorial statements, he tried to take precautions against a negative feeling in the group. Similarly, TM 3, the speaker of sentence (c), casually defines himself as an agreeable person in order to put an end to the lengthy disagreement with others. Laughter elicited by his statement shows that other members knew that it was untrue. His self-defining remark can be seen as a tactic to help restore the group rapport. All examples illustrate one characteristic of self-focused message which are sometimes used by Thai speakers as a shared interactive frame to defuse tension, balancing group equilibrium between task and rapport management. For non-Thais, however, who do not share this sort of frame, the assertion of the individual self in Thai interactive discourses may give an impression of Thai being egotistic.

\subsubsection{A summary of Thai group discussions}

In this section, we saw three characteristics of Thai social talk observed in group discussions. Firstly, Thai participants were inclined toward Individual-oriented topics and independent styles of talk and the message content is expressed mostly by verbs. The fact that patterns of interaction and participation are not as clear and consistent as in the Japanese groups, suggests preference for free styles and freedom of the self in interaction. The manifestation of this preference can be seen in various features of Thai interaction. I argue that this reflects a crucial Thai concept khwaam pen issarà 'independence' which largely shapes the speech behaviors of Thai speakers. While rapport management in Japanese groups deals with the comprehensiveness and the orderliness of the situation, in Thai groups it is the freedom and the enjoyment that one can experience in interacting with others.

Secondly, Thai speakers prefer to use intensifiers and spontaneous expressions to show involvement and create vividness in their interaction. Intensifying devices range from choices of strong lexis, intensifiers, emphatic particles, vocative, prosodic features, and a high-involvement participatory style. Intensifying effects and spontaneity create an amusing and friendly atmosphere or sanùk (literally meaning fun, enjoyment, having a good time) which is regarded as an important value in Thai social life.

Thirdly, speakers show less inhibition in projecting themselves as the focus in the 
interaction. Speakers want to strengthen their relationship with hearers by disclosing themselves. The self of the speakers and that of the hearers interact flexibly. Speakers may assert their self attributes during communication with others, although the degree of self-assertion is mitigated by contextualization cues speakers send out to frame the acts as play or sanùk. In the Thai social context, the presentation of self in a light-hearted manner not only helps lessen the degree of face-threat in the interaction but also helps the speakers process the task of negotiation more pleasantly. This speech behavior encourages openness and accessibility to the self of individuals in interaction. Rapport in Thai group interaction is seen to be built on personal ties which gradually expand and crisscross to form a whole body of group rapport as the interaction progresses.

These three features point out that rapport management among Thai social members is constructed largely on the structure of face management, that is, management of 'quality face' and 'identity face'. While quality face is concerned with the personal values and qualities speakers claim for themselves, identity face is the speaker's desire that their social identity, for example, as a group leader or as a close friend be acknowledged (Spencer-Oatey 2000). Face in Thai connotes personal aspects of one's personality, emotions and concept of honor (Ukosakul 2009). It is also often equated with ego (Komin 1990). Attention to each other's ego-self can be understood as a key in rapport management in Thai social interaction.

\section{Discussion}

In this study, I have explored how Japanese and Thai speakers engaged in social talk, with the aim of finding out the difference of rapport management in the two cultures. Lexical choices and content in the idea units indicate the way speakers establish common ground, the manner they deal with 'self', and the nature and degree of engagement they express in their discourse.

The findings show that rapport in Japanese social talk is formed by individuals compromising their selves to create a common area for overall participation. Interactants' consciousness tends to be drawn into a shared sphere, while their self tunes in the context and tries to find its relevancy within it. Ochiai (2008) (following Shimizu's (2003) egg model) drew an analogy between Japanese interaction and raw eggs that are poured into a container. While each yolk remains its shape and form, the egg white blends into one fluid body creating shared space for the yolks. Ochiai uses the metaphor of egg yolks to represent Japanese interactants' sense of self which is fluid and resilient, and of the egg white to represent the cognition of each individual which becomes one shared field during interaction.

The Japanese experience of self includes a sense of interdependence and of one's status as a participant in a larger social unit (Sampson 1988). The interdependent inclination entails Japanese speakers seeing themselves as part of an encompassing social relationship and recognizing that their behaviors are determined, subject to, and organized by what they perceive to be the thoughts, feelings, and actions of others in the relationship. The prominence of self is reduced to a minimum for the sake of group congruity. Generally speaking, in Japanese social talk, 1) communally shared topics are a prime concern, 2) the sense of individual self is not to be emphasized, and 3) if the self is to be expressed, then there is preferably some relevancy between the self and the 
group. Rapport management in Japanese groups places more emphases on sociality rights. Nevertheless, sociality rights in Japanese groups are not the rights one volitionally claims, but expectancies which are largely pre-determined in the contexts.

In comparison, rapport in Thai group interaction is constructed by participants showing the accessibility to each other's self and giving attention to the others' selves. Rapport construction starts from personal ties among in-groups, and gradually extends to form an extensive network. Thai relationships are primarily person-based and not so much institutionally defined (Mulder 1996). Several scholars (Benedict 1943; Embree 1950; Phillips 1965) have interpreted the Thai social system as 'loosely structured' where social process and institutional arrangement is unpredictable. Members often have multiple or even conflicting norms of what to do. In this loose structure, individuals have much more freedom to behave differently (Pelto 1968). This is in contrast to the typical 'tight-culture' of Japan in which conformity is deeply cultivated and there is less room for deviation. The key element of rapport construction in Thai concept is kan-een, meaning 'a pleasant, friendly atmosphere where people feel at home'. The word is composed of the adverb kan 'together', and the adverb eey 'by oneself'. Even in work places or business scenes, individual Thais appreciate an at-home interaction where one can be oneself as if in one's own home.

According to Triandis (1995), the degree of individualism or collectivism in any given culture is influenced by whether the culture is tight or loose. Individualism is most likely a consequence of looseness whereas collectivism is most often a consequence of tightness. Under this interpretation, Thai social interaction can be suitably described as loosely structured with an individualistic orientation. But how can we explain the contradictory findings of Hofestede's survey which shows collectivistic scores of Thai culture higher than that of Japan?

According to Hofestede (1991), the degree of individualism or collectivism is measured and defined by how much individuals rated the importance of some work-related values. Thais rate high on the collectivist scale because Thai workers often view themselves being dependent on their work place and personal relations with co-workers. Wichiarajote (1973) argues that Thai social relationships are principally based on personal motivations which are characterized by the need for affiliation and acceptance. He calls it an 'affiliative society', a society in which people are highly dependent on each other. People's behavior is influenced by the allegiance shown to their own group, as personal connections are considered important in Thai society (Holmes \& Tangtongtavy 1997)

In Komin's (1998) survey on Thai world views and values, Thai people generally answered that they placed a high value on self-reliance and independence. She believes this to be the influence of Thai Buddhism. Although Thais are not completely egocentric, they are less socio-centric than Japanese due to the existence of a strong sense of individualism in the Thai personality (Ubonsakul 2009). In sum, this study proves that in Thai social talk, 1) Individual oriented topics and particularity of elements often tend to be the focus of talk, 2) solidarity in interaction is shown by emphasizing the degree of involvement and intimacy, and 3) the selves of individual members are promoted and used as basis in forming rapport with others. 


\section{Conclusion}

Both Japanese and Thai people give importance to collectives. However, this paper shows that the people from these two cultures handle interpersonal relationships differently. These findings may offer some explanation to why Japanese people view Thais as disorderly and self-centered, while Thai people view Japanese as too serious, too formal and guarded about their personal feelings (Wuwongse \& Washiradilok 2001). Due to the different nature of rapport which has the concept of self as the underlying factor and different styles of rapport construction, it is predictable that when the two cultures engage in communication, problems are likely to occur. By casting light on these differences, I hope that this study leads to the development of guidelines for Thai and Japanese to recognize and deal with some of the conflicts caused by differences in communication styles.

\section{Transcription Conventions}

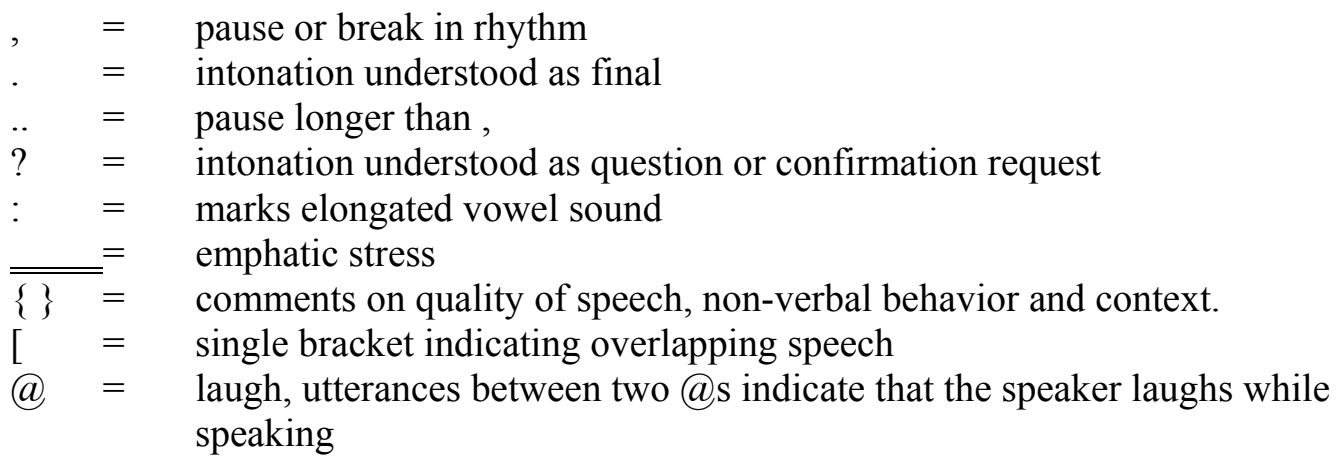

\section{References}

Bales, Robert F. (1976) Interaction process analysis: A method for the study of small groups. Chicago: University of Chicago Press.

Barnlund, Dean C. (1975) Public and private self in Japan and the United States. Tokyo: Simul Press.

Benedict, Ruth (1943) Thai culture and behavior: An unpublished war-time study dated September, 1943. Ithaca, New York: Cornell University.

Brosnahan, Leger (1990) Japanese and English gesture: Constructive nonverbal communication. Tokyo: Taishūkan.

Brown, Penelope, and Stephen C. Levinson (1987) Politeness: Some universals in language usage. Cambridge: Cambridge University Press.

Chafe, Wallace (1980) The deployment of consciousness. In W. Chafe (ed.), The pear stories: Cognitive, cultural, and linguistic aspects of narrative production. Norwood, NJ: Ablex, pp. 9-50.

Chafe, Wallace (1994) Discourse, consciousness, and time. Chicago: The University of Chicago Press. 
Cheng, Winnie (2003) Intercultural conversation. Amsterdam: John Benjamins Publishing Company.

Eggins, Suzanne, and Diana Slade (1997) Analysing casual conversation. London: Cassell.

Embree, John F. (1950) Thailand, a loosely structured social system. American Anthropologist 52: 181-93.

Goffman, Erving (1972) Interaction ritual: Essays on face-to-face behavior. Harmondsworth: Penguin.

Gumperz, John J. (1982) Discourse strategies. Cambridge: Cambridge University Press.

Halliday, Michael A. (1985) An Introduction to functional grammar. London: Edward Arnold.

Hasada, Rie (2006) Cultural scripts: Glimpses into the Japanese emotion world. In C. Goddard (ed.), Ethnopragmatics: Understanding discourse in cultural context. Berlin: Mouton de Gruyter, pp. 171-198.

Hofstede, Geert (1991) Culture and organizations: Software of the mind. London: McGraw Hill.

Hofstede, Geert (2003) Geert Hofstede ${ }^{\mathrm{TM}}$ cultural dimensions. 19 Nov $2009<$ http://www.geert-hofstede. $\mathrm{com} />$.

Honda, Atsuko (2002) Conflict management in Japanese public affairs talk shows. Journal of Pragmatics 34: 573-608.

Holmes, Henry, and Suchada Tangtongtavy (1997) Working with the Thais. Bangkok: White Lotus.

Ide, Sachiko (2006) Wakimae no goyōron. Tokyo: Taishūkan.

Iwasaki, Shoichi, and Preeya Ingkaphirom Horie (1998) The 'Northridge Earthquake' conversations: Conversational patterns in Japanese and Thai and their cultural significance. Discourse and Society 9.4: 501-529.

Komin, Suntaree (1998) The world view through Thai value systems. In A. Pongsapich (ed.), Traditional and changing Thai world view. Bangkok: Chulalongkorn University Press, pp. 207-228.

Kumagai, Tomoko (2004) The role of repetition in complaint conversations. In P. Szatrowski (ed.), Hidden and open conflict in Japanese conversational interaction. Tokyo: Kurosio Publishers, pp. 199-220.

Lebra, Takie Sugiyama (1976) Japanese patterns of behavior. Honolulu: University of Hawaii Press.

Lekawatana, Pongsri (1974) A contrastive study of English and Thai. Monterey, CA: Defense Language Institute.

Malinowski, Bronislaw (2006 [1926]) On phatic communion. In A. Jaworski and N. Coupland (eds.), The discourse reader, second edition. New York: Routledge, pp. 296-298.

Markus, Hazel R., and Shinobu Kitayama (1991) Culture and the self: Implications for cognition, emotion, and motivation. Psychological Review 98.2: 224-253.

Maynard, Senko K. (1989) Japanese conversation: Self-contextualization through structure and interactional management. Norwood, NJ: Ablex.

Media Monitor (2009)

$<$ http://www.oknation.net/blog/teammediamonitor/2009/05/07/entry-1> (accessed 19 November 2009)

Mizutani, Nobuko (1993) Kyōwa kara danwa e. Nihongo gaku 12.4: 4-10. 
Morita, Emi (2005) Negotiation of contingent talk: The Japanese interactional particles ne and sa. Amsterdam: John Benjamins Publishing Company.

Mulder, Neil (1996) Inside Thai society. Amsterdam: The Pepin Press.

National News Bureau (2009)

$<$ http://thainews.prd.go.th/previewnews.php?tb=NEWS\&m_newsid=255207090145> (accessed 19

November 2009)

Ochiai, Rumiko (2008) Gōi keisei kaiwa de hyōshutsu suru serufu to ba no riron-kakunin. Proceedings of the $21^{\text {st }}$ Japanese association of sociolinguistic sciences, March 22-23. Tokyo Woman's Christian University, Japan, pp. 76-79.

Pavlidou, Theodossia-Soula (2000) Telephone conversations in Greek and German: Attending to the relationship aspect of communication. In H. Spencer-Oatey (eds.), Culturally speaking: Managing rapport through talk across cultures. London: Continuum, pp. 121-142.

Pelto, Pertti J. (1968) The difference between "tight" and "loose" societies. Transaction 5: 37-40.

Phillips, Herbert P. (1965) Thai peasant personality. Berkeley: University of California Press.

Sampson, Edward E. (1988) The debate on individualism. American Psychologist 43: 15-22.

Scollon, Ron, and Suzanne Wong Scollon (2001) Intercultural communication: A discourse approach. Oxford: Blackwell.

Shimizu, Hiroshi (2003) Ba no Hassō. Tokyo: University of Tokyo Press.

Spencer-Oatey, Helen (2000) Rapport management: A framework for analysis. In H. Spencer-Oatey (ed.), Culturally speaking: Managing rapport through talk across cultures. New York: Continuum, pp. 11-45.

Straehle, Carolyn A. (1993) "Samuel?" "Yes, dear?": Teasing and conversational rapport. In D. Tannen (ed.), Framing in discourse. Oxford: Oxford University Press, pp. 210-230.

Tannen, Deborah (1984) Conversational style: Analyzing talk among friends. Oxford: Oxford University Press.

Triandis Harry C. (1995) Individualism \& collectivism. Boulder, CO: Westview Press.

Young, Linda W.L. (1994) Crosstalk and culture in Sino-American communication. Cambridge: Cambridge University Press.

Ubonsakul, Margaret (2009) Significance of 'face' and politeness in social interaction as revealed through Thai 'face' idioms. In F. Bargiela-Chiappini and M. Haugh (eds.), Face, Communication and Social Interaction. London: Equinox, pp. 289-305.

Uyeno, Tazuko (1971) A study of Japanese modality - A performative analysis of sentence particles. Ph.D. dissertation. University of Michigan.

Wichiarajote, Weerayuth (1973) The theory of affiliative society. Bangkok: College of Education, Prasanmitr, pp.118-119. cited in Steven Piker (1975). The psychological study of Theravada societies. Netherlands: Brill Academic Publishers.

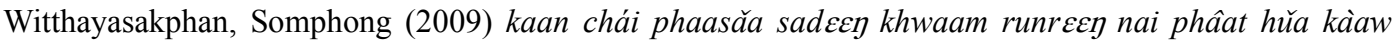
aachayaakam nai nănsǔuphim raai wan.

$<$ http://www.human.cmu.ac.th/ thai/sompong/res_kalaya1.doc> (accessed 19 November 2009) 
Wuwongse, Warintorn, and Weerawan Washiradirok (2001) Comparison of Thai and Japanese viewpoints towards each other. Warasarn Silapasart 1.1: 194-215.

ATAYA AOKI is completing a Ph.D. in linguistic communication at the Graduate School of International Cultural Studies, Tohuku University, Sendai, Japan. She is currently teaching Thai language at Miyagi Gakuin Women's University, Sendai and also works as an international tourism specialist at the Sendai City Economic Affairs Bureau.

Address: The Graduate School of Intercultural Studies, Tohoku University, 7-29-32 Sakuragaoka, Aoba-ku, Sendai 981-0961, Japan. Tel. and fax: 81-(0)22-279-4479; e-mail: awesome.sendai@gmail.com 